\title{
Podophyllotoxin Isolated from Podophyllum peltatum Induces G2/M Phase Arrest and Mitochondrial- Mediated Apoptosis in Esophageal Squamous Cell Carcinoma Cells
}

\author{
Goo Yoon ${ }^{1,+}{ }^{\oplus}$, Mee-Hyun Lee ${ }^{2,3,+}$, Ah-Won Kwak ${ }^{1}, \mathrm{Ha}^{-N a} \mathrm{Oh}^{1}{ }^{1}$, Seung-Sik Cho ${ }^{1}{ }^{1}$, \\ Joon-Seok Choi ${ }^{4}$, Kangdong Liu ${ }^{2,3}$, Jung-Il Chae ${ }^{5, *(D)}$ and Jung-Hyun Shim ${ }^{1,2, *(D)}$ \\ 1 Department of Pharmacy, College of Pharmacy, Mokpo National University, Jeonnam 58554, Korea; \\ gyoon@mokpo.ac.kr (G.Y.); rhkrdkdnjs12@mokpo.ac.kr (A.-W.K.); 17392303@mokpo.ac.kr (H.-N.O.); \\ sscho@mokpo.ac.kr (S.-S.C.) \\ 2 The China-US (Henan) Hormel Cancer Institute, Zhengzhou 450008, China; mhlee@hci-cn.org (M.-H.L.); \\ kangdongliu@126.com (K.L.) \\ 3 Basic Medical College, Zhengzhou University, Zhengzhou 450001, China \\ 4 College of Pharmacy, Daegu Catholic university, Havang-Ro 13-13, Havang-Eup, Gyeongsan-si, \\ Gyeongbuk 38430, Korea; joonschoi@cu.ac.kr \\ 5 Department of Dental Pharmacology, School of Dentistry, BK21 Plus, Jeonbuk National University, \\ Jeonju 54896, Korea \\ * Correspondence: jichae@jbnu.ac.kr (J.-I.C); s1004jh@gmail.com (J.-H.S.); Tel.: +82-63-270-4024 (J.-I.C.); \\ +82-61-450-2684 (J.-H.S.); Fax: +82-63-270-4037 (J.-I.C.); +82-61-450-2689 (J.-H.S.) \\ + These authors contributed equally to this work as co-first authors.
}

Received: 12 November 2019; Accepted: 14 December 2019; Published: 18 December 2019

\begin{abstract}
Esophageal squamous cell carcinoma (ESCC) is one of the most common cancers in East Asia and is the seventh leading cause of cancer deaths. Podophyllotoxin (PT), a cyclolignan isolated from podophyllum peltatum, exhibits anti-cancer effects at the cellular level. This study investigated the underlying mechanism of anti-cancer effects induced by PT in ESCC cells. Exposure to increasing concentrations of PT led to a significant decrease in the growth and anchorage-independent colony numbers of ESCC cells. PT showed high anticancer efficacy against a panel of four types of ESCC cells, including KYSE 30, KYSE 70, KYSE 410, KYSE 450, and KYSE 510 by $\mathrm{IC}_{50}$ at values ranges from 0.17 to $0.3 \mu \mathrm{M}$. We also found that PT treatment induced G2/M phase arrest in the cell cycle and accumulation of the sub-G1 population, as well as apoptosis. Exposure to PT triggered a significant synthesis of reactive oxygen species (ROS), a loss of mitochondrial membrane potential (MMP), and activation of various caspases. Furthermore, PT increased the levels of phosphorylated c-Jun N-terminal kinase (JNK), p38, and the expression of Endoplasmic reticulum (ER) stress marker proteins via ROS generation. An increase in the level of pro-apoptotic proteins and a reduction in the anti-apoptotic protein level induced ESCC cell death via the loss of MMP. Additionally, the release of cytochrome $\mathrm{c}$ into the cytosol with Apaf- 1 induced the activation of multi-caspases. In conclusion, our results revealed that PT resulted in apoptosis of ESCC cells by modulating ROS-mediated mitochondrial and ER stress-dependent mechanisms. Therefore, PT is a promising therapeutic candidate as an anti-cancer drug against ESCC for clinical use.
\end{abstract}

Keywords: ESCC (Esophageal squamous cell carcinoma); podophyllotoxin; ROS (reactive oxygen species); p38; JNK (c-Jun N-terminal kinase) 


\section{Introduction}

Esophageal malignancies can be classified into adenocarcinoma and esophageal squamous cell carcinoma (ESCC). ESCC is the one of common malignant neoplasms in the worldwide, accounting for about $80 \%$ of the overall esophageal cancer-related deaths annually [1]. It originates from the esophageal epithelium, mainly the proximal and mid-esophagus [1,2]. Despite treatment of numerous cases of ESCC cancer with neoadjuvant chemoradiation or other primary treatments, almost $50 \%$ of patients suffer from recurrence [3]. The majority of therapies using HER2/neu (human epidermal growth factor receptor 2), EGFR (epidermal growth factor receptor), and VEGF (vascular endothelial growth factor) for ESCC are in clinical trials, with no remarkable findings [2]. Therefore, advances that can potentially decrease the adverse effects of conventional chemotherapy and improve the prognosis of patients are needed.

Natural products, such as plant extracts or isolates, show the benefits of less toxicity and low cost and also demonstrate anticancer, antioxidant, anti-inflammatory, and antibacterial properties [4-6]. Podophyllotoxin (PT) has been used as an herbal drug in traditional folk remedies for preventive and therapeutic applications for more than 1000 years. PT, one of the active cyclolignan compounds extracted from Podophyllum peltatum and P. hexandrum, has been reported to provide beneficial effects in patients with intestinal Ascaris lumbicoides-induced symptoms, venereal warts, lymphoma, and cancers $[7,8]$. Compelling reports have demonstrated that PT-derived anticancer drugs play a powerful role in inhibiting topoisomerase II activity and inducing apoptosis of several types of cancers, including female-related tumors, non-Hodgkin's lymphomas, and lung cancers $[4,8,9]$. PT also exhibits therapeutic activity in inducing cell cycle arrest (G2/M) by inhibiting the microtubule assembly [10]. Therefore, it is necessary to establish how cellular targets mediate the effects of PT to develop antitumor therapies against esophageal cancer.

Apoptosis plays an important role in eliminating damaged cells [11]. Endoplasmic reticulum (ER) stress is a cellular response produced by the accumulation of unfolded or misfolded proteins, which is related to apoptosis [12]. During sustained ER stress, the C/EBP homologous protein (CHOP), one of the death-related transcription factors, triggers the transcription of apoptosis-related genes, including Bcl-2 family proteins, death receptor (DR) 4, DR5, and Puma [13]. Anti-apoptotic proteins, such as $\mathrm{Bcl}-2$ and Mcl-1, are crucial in maintaining mitochondrial functions, while pro-apoptotic proteins, such as bcl-2-like protein 4 (Bax), Bak, and Bid, promote the release of cytochrome c (cyto c) [14]. Reactive oxygen species (ROS), such as superoxide anion radicals and hydroxyl radicals, are chemically reactive molecules produced by common metabolic processes. A significant increase in ROS induces oxidative stress that can be deleterious to multiple organelles and enzymes in the cell [15]. In a recent study, ROS regulated the mitogen-activated protein kinase (MAPK) pathway [16]. MAPK comprises extracellular signal-regulated kinase (ERK), c-Jun N-terminal kinase (JNK), and p38 and plays an important role in cell proliferation and apoptosis signaling pathways $[17,18]$.

The role of PT as an anticancer agent in ESCC has yet to be studied. The purpose of this study is to elucidate whether the anti-cancer effect of PT on esophageal cell lines (KYSE 30 and KYSE 450) is mediated via the JNK/p38 MAPK signaling pathway.

\section{Materials and Methods}

\subsection{Reagents}

Cell culture medium (RPMI-1640), fetal bovine serum (FBS), phosphate-buffered saline (PBS), penicillin, streptomycin, and trypsin were purchased from Hyclone (Logan, UT, USA) or Welgene (Daegu, Korea). Antibodies against JNK, phospho-JNK (p-JNK) (Thr183/Try185), p38, and phospho-p38 (p-p38) (Thr180/Try182) were purchased from Cell Signaling Technology (Danvers, MA, USA). The primary antibodies against $\beta$-actin, p21, p27, cell division cycle protein (cdc2), cyclin B1, CHOP, DR4, DR5, glucose response protein 78 (GRP78), Mcl-1, Bcl-2, Bax, cyto c, $\alpha$-tubulin, COX4, Apaf-1, and cleaved-poly ADP-ribose polymerase (c-PARP) were purchased from Santa Cruz 
Biotechnology (Santa Cruz, CA, USA). The CellTiter 96 ${ }^{\circledR}$ AQueous One Solution was obtained from Promega (Madison, WL, USA). Dimethyl sulfoxide (DMSO) and PT were bought from Sigma-Aldrich (St. Louis, MO, USA).

\subsection{Cell Culture}

KYSE 30, KYSE 70, KYSE 410, KYSE 450, and KYSE 510 cells are human ESCC cell lines obtained by the Type Culture Collection of the Chinese Academy of Sciences (Shanghai, China). These cell lines were cultured in an RPMI 1640 medium containing 10\% FBS, $100 \mathrm{U} / \mathrm{mL}$ penicillin, and streptomycin at $37^{\circ} \mathrm{C}$ in a humidified incubator containing $5 \% \mathrm{CO}_{2}$.

\subsection{MTS Assay}

To evaluate the cytotoxicity of PT, cell viability was determined using an 3-(4,5-dimethylthiazol2-yl)-5-(3-carboxymethoxyphenyl)-2-(4-sulfophenyl)-2H-tetrazolium inner salt (MTS) assay. Briefly, the KYSE 30, KYSE 70, KYSE 410, KYSE 450, and KYSE 510 cells were seeded into 96-well plates at different densities, as follows: $2.75 \times 10^{3} /$ well, $10 \times 10^{3} /$ well, $2.5 \times 10^{3} /$ well, $3.5 \times 10^{3} /$ well, and $5.5 \times 10^{3} /$ well, respectively. The cells were exposed to different concentrations of PT for $24 \mathrm{~h}$ and $48 \mathrm{~h}$ and incubated with CellTiter $96^{\circledR}$ AQueous One Solution for $2 \mathrm{~h}$. The absorbance was read by a spectrophotometer (Thermo Fisher Scientific, Vantaa, Finland) at $490 \mathrm{~nm}$.

\subsection{Soft Agar Assay}

To establish colony growth by KYSE 30 and KYSE 450 cells in the soft agar, the 6-well plates were coated with $0.6 \%$ agarose in a BME medium, FBS, L-glutamine, and gentamicin with or without PT. Subsequently, the 8000 cells were layered on the agarose at the bottom comprising $0.3 \%$ agarose in a BME medium, FBS, L-glutamine, and gentamicin mixed with DMSO or PT. After two weeks, the colonies were counted, and images were observed on a phase contrast inverted microscope (Leica Microsystems, Wetzlar, Germany).

\subsection{Cell Cycle Distribution Analysis}

Cells were incubated with a range of PT doses $(0.2$ to $0.4 \mu \mathrm{M})$ for $48 \mathrm{~h}$. Following PT exposure, the cells were washed three times with PBS and fixed with $70 \%$ ice cold ethanol for $24 \mathrm{~h}$. The fixed cells were stained with Muse ${ }^{\mathrm{TM}}$ Cell cycle reagent (Merck Millipore, Billerica, MA, USA) for 30 min at $37^{\circ} \mathrm{C}$ in the dark. The cell cycle distribution was measured using a Muse ${ }^{\mathrm{TM}}$ Cell Analyzer (Merck Millipore, Billerica, MA).

\subsection{Annexin V/7-Aminoactinomycin D (7-AAD) Stained Cell Counting}

KYSE 30 and KYSE 450 cells were seeded in 6-well plates. Cells were incubated for $48 \mathrm{~h}$ in the presence of PT and then harvested. Both cell lines were stained with Muse ${ }^{\mathrm{TM}}$ Annexin V and Dead Cell Reagent (Merck Millipore, Billerica, MA, USA) for $30 \mathrm{~min}$ at $37^{\circ} \mathrm{C}$ in the dark. The stained cells were detected using a Muse ${ }^{\mathrm{TM}}$ Cell Analyzer.

\subsection{Western Blots}

The cells were harvested by a scraper and washed with ice-cold $1 \times$ PBS, three times. The total proteins of the KYSE 30 and KYSE 450 cell lysates were separated on 10\%, 12\%, and 15\% SDS-PAGE gels and transferred to a polyvinylidene fluoride membrane. To block nonspecific binding, 3-5\% nonfat dry milk in PBST (PBS containing 0.1\% Tween 20) was added to the membrane for $2 \mathrm{~h}$ at room temperature (RT) followed by incubation of the membrane with the target primary antibody overnight at $4{ }^{\circ} \mathrm{C}$. The membrane was washed with PBST for $30 \mathrm{~min}$ and incubated with appropriate horseradish peroxidase-conjugated secondary antibody for $2 \mathrm{~h}$ at RT, followed by visualization using 
an ECL Plus Western Blotting Detection system (Santa Cruz Biotechnology). The proteins were detected using an ImageQuant LAS 500 (GE Healthcare, Uppsala, Sweden).

\subsection{ROS Assay}

In order to determine the intracellular changes underlying ROS generation, a Muse ${ }^{\mathrm{TM}}$ Oxidative Stress Kit (Merck Millipore, Billerica, MA, USA) was used to measure the intracellular ROS levels in the cells of each treatment group. KYSE 30 and KYSE 450 cells were seeded on 6-well plates and treated with PT for $48 \mathrm{~h}$. The cells were harvested and stained with a Muse ${ }^{\mathrm{TM}}$ Oxidative Stress Reagent in the cell incubator at $37^{\circ} \mathrm{C}$ for $30 \mathrm{~min}$. A Muse ${ }^{\mathrm{TM}} \mathrm{Cell}$ Analyzer can be used to measure the intracellular ROS levels.

\subsection{Measurement of Mitochondrial Membrane Potential}

To evaluate the level of mitochondrial membrane potential (MMP, $\triangle \Psi \mathrm{m}$ ), ESCC cells were treated with DMSO or PT $(0.2$ to $0.4 \mu \mathrm{M})$ for $48 \mathrm{~h}$. The cells were washed with a $1 \mathrm{X}$ assay buffer and stained with Muse ${ }^{\mathrm{TM}}$ MitoPotential Dye (Merck Millipore, Billerica, MA, USA) for $20 \mathrm{~min}$ in the $\mathrm{CO}_{2}$ incubator, followed by supplementation of the samples with 7-AAD (Merck Millipore, Billerica, MA, USA). The MMP measurement was conducted using a Muse ${ }^{\mathrm{TM}}$ Cell Analyzer.

\subsection{Cytosolic and Mitochondrial Fractionation}

Cytosolic and mitochondrial fractions were generated using digitonin-based subcellular fractionation methods reported previously [19]. The cells were resuspended in a plasma membrane extraction buffer [ $250 \mathrm{mM}$ sucrose, $10 \mathrm{mM}$ HEPES ( $\mathrm{pH} 8.0$ ), $10 \mathrm{mM} \mathrm{KCl}, 1.5 \mathrm{mM} \mathrm{MgC} 2 \cdot 6 \mathrm{H}_{2} \mathrm{O}, 1 \mathrm{mM}$ EDTA, $1 \mathrm{mM}$ EGTA, $0.1 \mathrm{mM}$ phenylmethylsulfonyl fluoride, $0.01 \mathrm{mg} / \mathrm{mL}$ aprotinin, and $0.01 \mathrm{mg} / \mathrm{mL}$ leupeptin] with $0.05 \%$ digitonin. After centrifugation at $13,000 \mathrm{rpm}$ for $5 \mathrm{~min}$ at $4{ }^{\circ} \mathrm{C}$, the cytosolic fraction was recovered. The pellet was washed with cytosolic membrane extraction buffer twice and homogenized with the same buffer containing $0.5 \%$ Triton X-100. Mitochondrial extracts were recovered by centrifugation at $13,000 \mathrm{rpm}$ for $30 \mathrm{~min}$ at $4{ }^{\circ} \mathrm{C}$.

\subsection{Caspase Activity}

The activities of caspase- $1,-3,-4,-5,-6,-7,-8$, and -9 were determined using a Muse ${ }^{\mathrm{TM}}$ Multi-Caspase Kit from Merck Millipore. Multi-Caspase activity was analyzed after treatment with DMSO or under different concentrations of PT for $48 \mathrm{~h}$. The treated cells were resuspended in $1 \times$ Caspase Buffer. The cells were stained with a Muse ${ }^{\mathrm{TM}}$ Multi-Caspase Reagent and a 7-AAD working solution. The multi-caspase activity was analyzed using a Muse ${ }^{\mathrm{TM}}$ Cell Analyzer.

\subsection{Statistical Analysis}

The data are presented as the means \pm SD. Statistical analysis was performed using the Prism 5.0 statistical package. The statistical significance of differences between groups was analyzed using ANOVA. The mean values were considered statistically significant at $p<0.05$. In the present study, the data represent experiments performed three times in triplicate.

\section{Results}

\subsection{PT Suppresses ESCC Cell Proliferation and Colony-Forming Ability}

To investigate the roles of PT in ESCC cells, we conducted an MTS assay to evaluate cell proliferation. PT $(0.1,0.2,0.3$, and $0.4 \mu \mathrm{M})$ treatment for $24 \mathrm{~h}$ and $48 \mathrm{~h}$ significantly decreased the cell proliferation of ESCC cells (KYSE 30, KYSE 70, KYSE 410, KYSE 450, and KYSE 510) in a concentration-dependent manner (Figure 1B-F). After $48 \mathrm{~h}$ of PT treatment, the half-maximal inhibitory concentrations ( $\mathrm{IC}_{50}$ ) of PT were $0.27 \mu \mathrm{M}$ (KYSE 30), $0.3 \mu \mathrm{M}$ (KYSE 70), $0.17 \mu \mathrm{M}$ (KYSE 410), $0.3 \mu \mathrm{M}$ (KYSE 450), and $0.3 \mu \mathrm{M}$ (KYSE 510). The colony formation assay was conducted to confirm another type of anti-proliferative 
effect of PT on KYSE 30 and KYSE 450 cells. Both the colony number and size were counted after PT treatment for 14 days. As shown in Figure 1G,H, the colony formation in both ESCC cells was significantly suppressed under elevated concentrations of PT. These results indicated that PT inhibits the growth of ESCC cells. To identify whether the cell growth suppression with PT was triggered by apoptosis, ESCC cells, KYSE 30, and KYSE 450 treated with PT were stained with Annexin V/7-AAD and analyzed via flow cytometry. In KYSE 30 cells, the total percentages of cells stained positive with Annexin V (early and late apoptosis) were $3.10 \pm 0.38 \%, 7.14 \pm 1.49 \%, 26.77 \pm 1.58 \%$, and $56.68 \pm 1.04 \%$ after treatment with PT at $0,0.2,0.3$, and $0.4 \mu \mathrm{M}$, respectively, for $48 \mathrm{~h}$ (Figure 1I). Similarly, treating KYSE 450 cells for $48 \mathrm{~h}$ increased the total percentage of apoptotic cells (early and late apoptosis) from $4.97 \pm 0.33 \%$ at the basal level (PT $0 \mu \mathrm{M})$ to $6.42 \pm 0.17 \%, 10.11 \pm 0.86 \%$ and $56.01 \pm 1.49 \%$ with PT 0.2 , 0.3 , and $0.4 \mu \mathrm{M}$, respectively. Thus, our data indicate that treatment with PT reduced cell viability and promoted apoptosis in ESCC cells. 
A<smiles></smiles>

podophyllotoxin (PT)

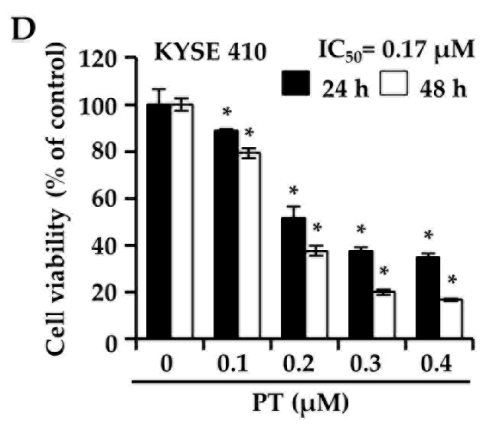

B

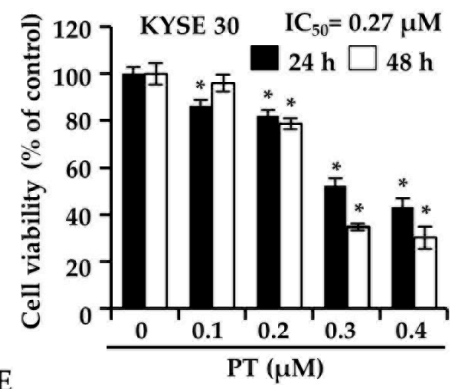

E

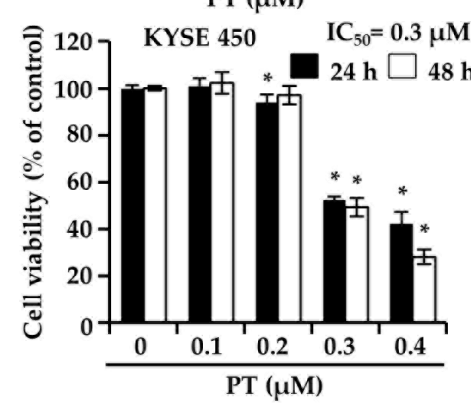

$\mathrm{C}$ ㅎิ 120$] \quad$ KYSE 70 $\mathrm{IC}_{50}=0.3 \mu \mathrm{M}$

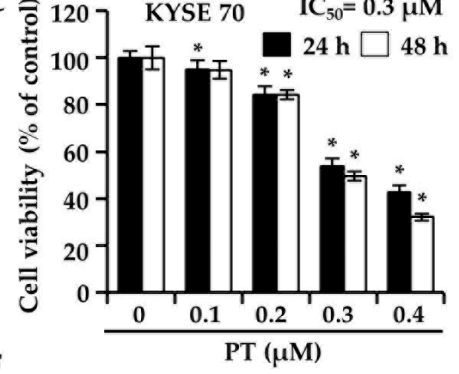

$\mathbf{F}$

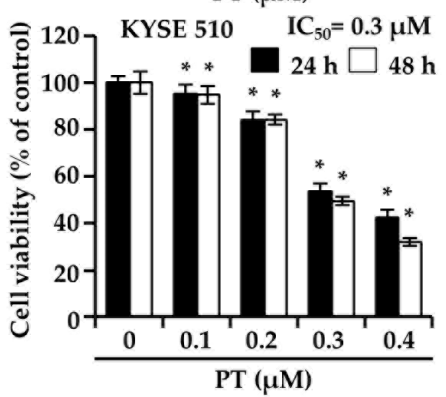

G
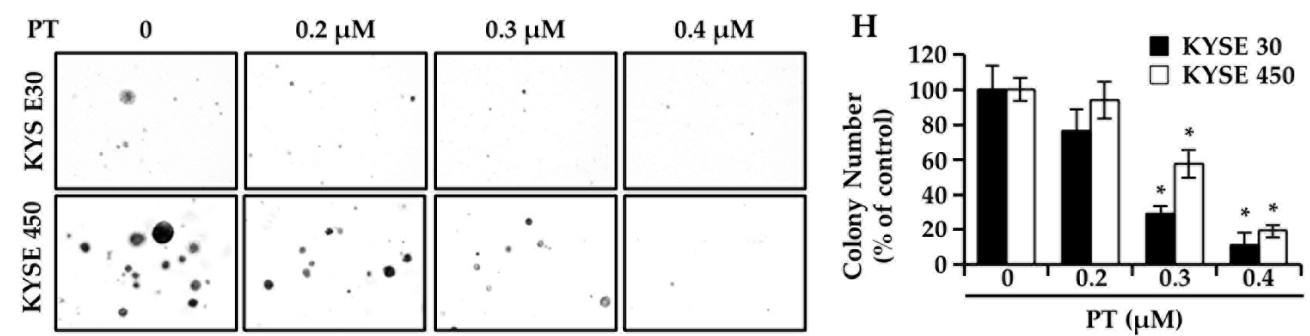

I
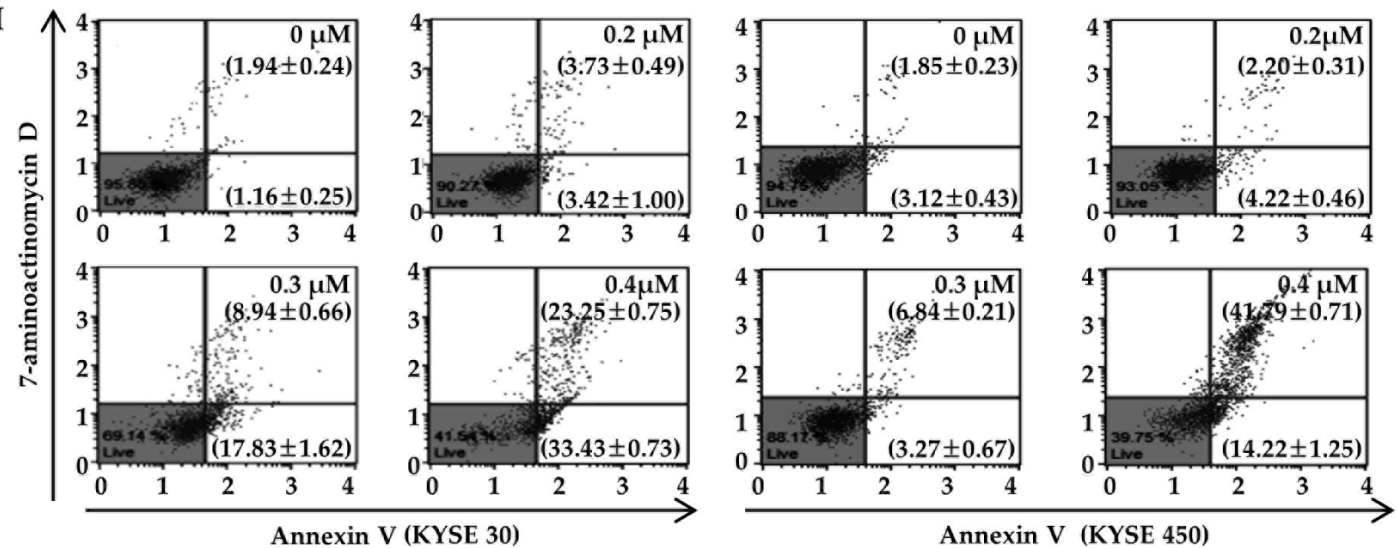

Annexin V (KYSE 450)

Figure 1. Inhibitory effects of podophyllotoxin (PT) on the cell growth of esophageal squamous cell carcinoma (ESCC) cell lines. (A) Chemical structure of PT. (B-F) MTS cell proliferation assays for P KYSE 30, KYSE 70, KYSE 410, KYSE 450, and KYSE 510 cells treated with increasing concentrations of the indicated PT $(0.1 \mu \mathrm{M}, 0.2 \mu \mathrm{M}, 0.3 \mu \mathrm{M}$, and $0.4 \mu \mathrm{M})$ for $24 \mathrm{~h}$ and $48 \mathrm{~h}$. Experiments were replicated in triplicate as the means $\pm \mathrm{SD}$. ${ }^{*} p<0.05$. (G) Anchorage-independent cell growth was evaluated by a soft agar assay. KYSE 30 and KYSE 450 cells were incubated with different concentrations of PT $(0 \mu \mathrm{M}, 0.2 \mu \mathrm{M}, 0.3 \mu \mathrm{M}$, and $0.4 \mu \mathrm{M})$ in soft agar plates for 14 days. Representative colonies formed in soft agar from ESCC cells were photographed. Each experiment was conducted in triplicate. $(\mathbf{H})$ The colonies were counted, and the data were plotted. Data are expressed as the mean $\pm \mathrm{SD}$. ${ }^{*} p<0.05$ versus control cells. (I) Representative dot plot of the Annexin V/7-AAD assay in ESCC cells. The cells were stained with Muse ${ }^{\mathrm{TM}}$ Annexin $\mathrm{V}$ and a dead cell reagent and analyzed using a Muse ${ }^{\mathrm{TM}}$ Cell Analyzer. The proportion of live cells is indicated in the lower left quadrant (Annexin V-/7-AAD-), the cells in early apoptosis are shown in the lower right quadrant (Annexin V+/7-AAD-), and the ones in late apoptosis are represented in the upper right quadrant (Annexin $\mathrm{V}+/ 7-\mathrm{AAD}+$ ). 


\subsection{PT Induces G2/M Phase Arrest of Cell Cycle in KYSE 30 and KYSE 450 Cells}

To determine the effect of PT on cell cycle arrest and cell death in ESCC cells, we used flow cytometry to analyze the cell cycle distribution and quantify the sub-G1 cell fraction as a marker for cell death upon treatment of KYSE 30 and KYSE 450 cells with PT ( 0.2 to $0.4 \mu \mathrm{M})$ for $48 \mathrm{~h}$. Compared with the untreated control, PT treatment affected the number of cells in the G0/G1 phase resulting in an appreciable arrest of ESCC cells at the G2/M phase of the cell cycle (Figure 2A). Exposure to PT $(0.4 \mu \mathrm{M})$ for $48 \mathrm{~h}$ led to the accumulation of cells in the sub-G1 fraction, increasing by $52.87 \pm 2.22 \%$ in KYSE 30 cells and $51.73 \pm 2.21 \%$ in KYSE 450 cells compared with the control $(4.43 \pm 0.25 \%$ and $5.97 \pm 0.15 \%)$, respectively (Figure 2B). To further examine the effect of PT on the G2/M phase arrest of KYSE 30 and KYSE 450 cells, we evaluated changes in the expression of checkpoint proteins using western blot. In Figure 2C, the expression of p21 and p27, which acts as a tumor suppressor protein, was significantly elevated in both cell lines following PT treatment at concentrations of $0.2,0.3$, and $0.4 \mu \mathrm{M}$ for $48 \mathrm{~h}$. In contrast, the expression of cdc2 and cyclin B1, which are major regulators of the G2-to-M phase transition, was markedly inhibited in both cell lines. Therefore, compared with the untreated controls, PT treatment induced cell cycle arrest at the G2/M phase and the sub-G1 fraction of ESCC cells.

A

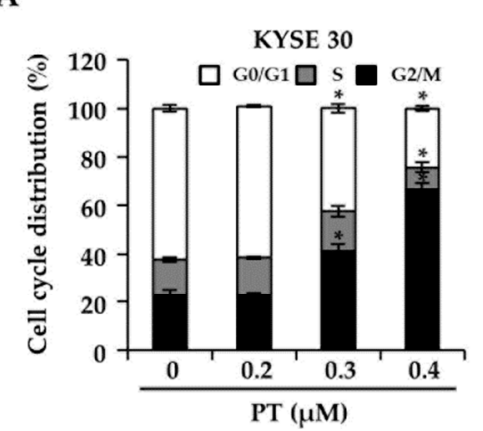

B

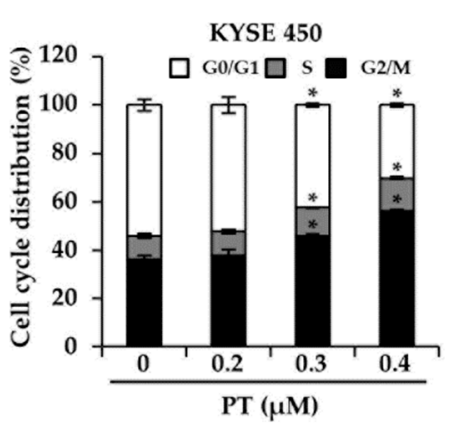

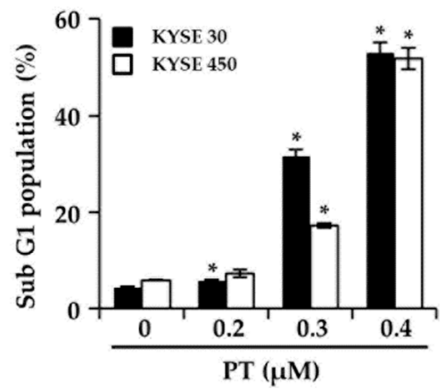

C

KYSE 30

KYSE 450

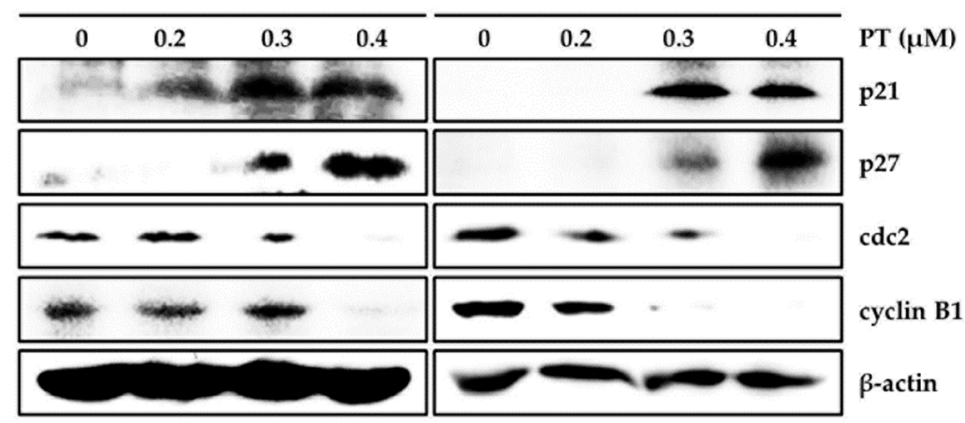

Figure 2. Effect of PT on cell cycle arrest in ESCC cells. KYSE 30 and KYSE 450 cells were cultured without and with PT $(0.2,0.3$, and $0.4 \mu \mathrm{M})$ for $48 \mathrm{~h}$. Cells were harvested, stained with Muse ${ }^{\mathrm{TM}}$ Cell cycle reagent, and analyzed to determine the cell cycle stages (A) and sub-G1 (B). Data are presented as the mean $(n=3) \pm \mathrm{SD}$ derived from three independent experiments. ${ }^{*} p<0.05$ against control. (C) The expression of cell cycle regulators and inhibitors. Cell lysates were assessed by western blotting analysis using specific antibodies for p21, p27, cdc2, and cyclin B1. Protein loading was normalized based on $\beta$-actin. Data are representative of three independent experiments.

\subsection{PT Induces Intracellular ROS Generation and Activates ROS-Dependent MAPK Pathway}

To elucidate whether PT mediated the synthesis of intracellular ROS, ROS production was evaluated in ESCC cells using the Muse ${ }^{\mathrm{TM}}$ Oxidative Stress Kit after PT treatment for $48 \mathrm{~h}$ (Figure 3A). Intriguingly, we observed intracellular ROS accumulation when cells were treated with DMSO or PT $(0.4 \mu \mathrm{M})$, increasing from $2.74 \pm 0.64 \%$ to $31.15 \pm 1.15 \%$ in KYSE 30 cells and $8.36 \pm 0.90 \%$ to $43.88 \pm 0.80 \%$ in KYSE 450 cells (Figure $3 \mathrm{~A}$ ). We also examined the expression of ER stress-related 
signaling molecules by treating ESCC cells with PT for $48 \mathrm{~h}$ followed by subsequent western blot analysis (Figure 3B). PT treatment dose-dependently increased the levels of CHOP, DR4, DR5, and GRP78 levels in KYSE 30 and KYSE 450 cells (Figure 3B). These data suggest that ER stress-induced proteins may be associated with apoptotic effects of PT in ESCC cells. Next, the effect of PT on the activation of the MAPK cascade in KYSE 30 and KYSE 450 cells was assessed by a western blot analysis. As shown in Figure 4, PT treatment resulted in a dose-dependent induction of p-JNK and p-p38 compared with the total JNK and p38 or $\beta$-actin levels. Our findings suggest that the PT-activated JNK and p38 signaling pathways may be regulated by ROS generation.
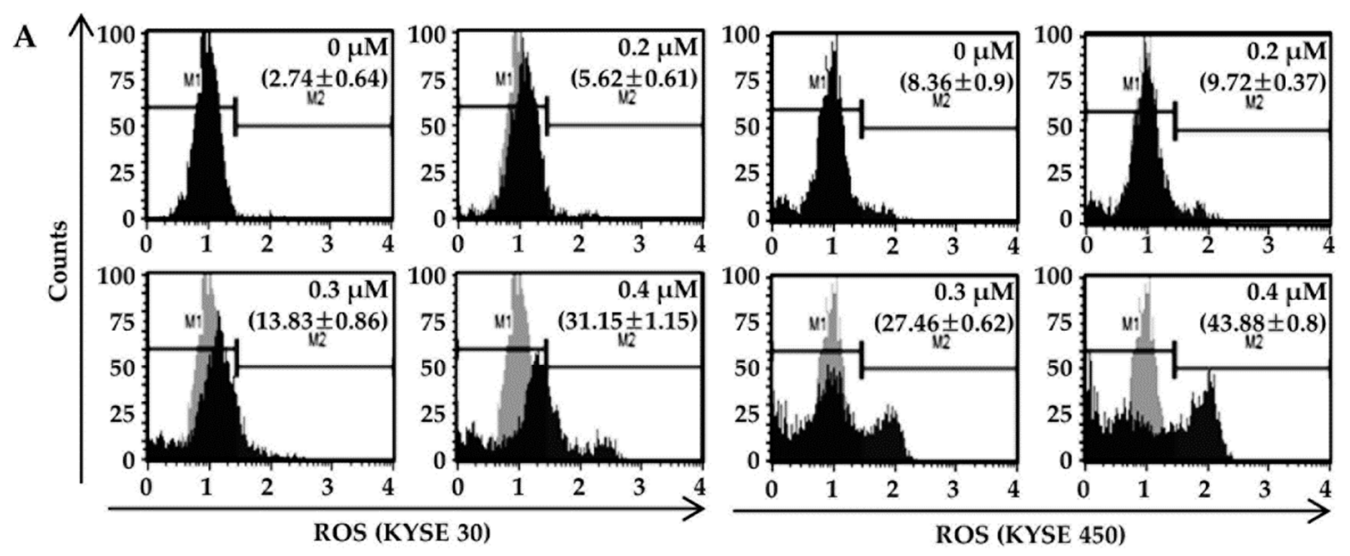

B

KYSE 30

KYSE 450

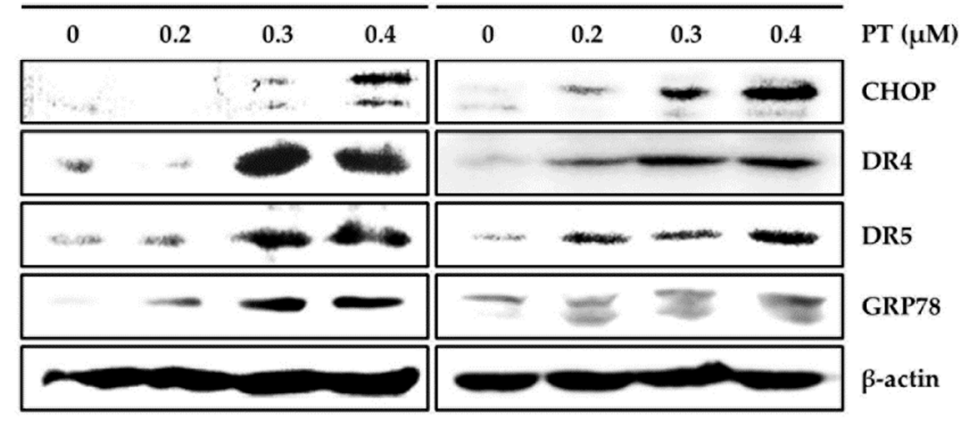

Figure 3. Effect of PT on ROS-mediated cell death. The ESCC cells were exposed to the indicated concentrations of PT for $48 \mathrm{~h}$. (A) The amount of intracellular ROS was assessed using a Muse ${ }^{\mathrm{TM}}$ Oxidative Stress Kit and a Muse ${ }^{\mathrm{TM}}$ Cell Analyzer. "M1" and "M2" represent ROS-negative or ROS-positive cells, respectively. (B) The protein expression of CHOP, DR4, DR5, and GRP78 was also visualized by western blot analysis. Protein loading was normalized based on $\beta$-actin. Data are representative of three independent experiments. 


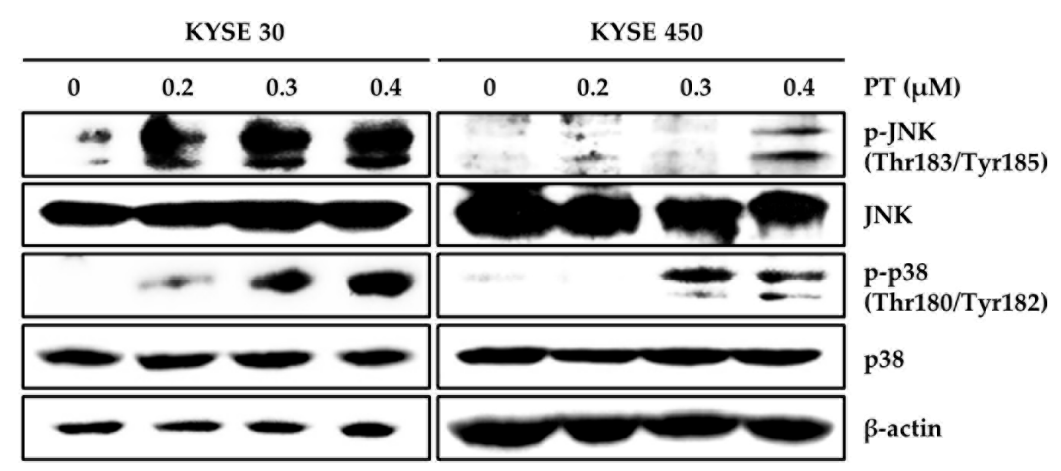

Figure 4. Effect of PT on the MAPK signaling pathway. The KYSE 30 and KYSE 450 cells were treated with various concentrations of PT and incubated for $48 \mathrm{~h}$. Cell lysates were analyzed by western blot using specific antibodies, including pJNK, JNK, p-p38, p38 MAPK, and $\beta$-actin antibodies. $\beta$-actin served as the loading control. Data are representative of three independent experiments.

\subsection{PT Induces Apoptosis of ESCC Cells via Reduction of Mitochondrial Membrane Potential and its Pathway}

To determine whether PT-induced apoptosis was mediated via mitochondrial dysfunction, we measured MMP using a Muse ${ }^{\mathrm{TM}}$ MitoPotential Kit in PT-treated KYSE 30 and KYSE 450 cells (Figure 5A). We confirmed a concentration-dependent increase in the mean percentages of total depolarization in KYSE 30 cells, from $2.35 \pm 1.96 \%$ in the untreated control to $11.77 \pm 1.06 \%, 20.50 \pm 0.71 \%$, and $58.97 \pm 6.29 \%$ in the presence of $0.2,0.3$, and $0.4 \mu \mathrm{M}$ of PT (Figure 5A). Untreated KYSE 450 cells showed a total depolarization change of $4.97 \pm 0.20 \%$, which increased to $8.72 \pm 0.24 \%, 19.53 \pm 0.83 \%$, and $37.43 \pm 2.20 \%$ after treatment with a $0.2,0.3$, and $0.4 \mu \mathrm{M}$ dose of PT. These results suggest that the induction of apoptosis in ESCC cells may be attributed to mitochondrial dysfunction. To further elucidate the role of PT in mitochondria-mediated apoptosis, we examined whether PT regulated the expression of pro- and anti-apoptotic proteins in ESCC cells using western blot analysis. As shown in Figure 5B, ESCC cells treated with increasing concentrations of PT exhibited augmented expression of Bax, Apaf-1, and C-PARP proteins, while the expression of Mcl-1 and Bcl-2 proteins was reduced. The results reflect a concentration-dependent increase in cytosolic cyto $\mathrm{c}$ after treatment with PT. Simultaneously, there was a decrease in cyto $\mathrm{c}$ in the mitochondrial fraction. In order to investigate the mitochondrial signals activating caspase activity following PT treatment, we analyzed the activity of multiple caspases (caspase-1, -3, -4, -5, -6, -7, -8, and -9) in KYSE 30 and KYSE 450 cells treated with different concentrations of PT for $48 \mathrm{~h}$ using a Muse ${ }^{\mathrm{TM}}$ Cell Analyzer (Figure 6). Flow cytometric analysis demonstrated that PT significantly induced caspase activation in a dose-dependent manner (Figure 6). The total apoptotic phenotype (multi caspase-positive/7-AAD-positive and negative) increased from $6.63 \pm 0.41 \%$ to $11.51 \pm 1.63 \%, 22.60 \pm 4.73 \%$, and $51.81 \pm 0.75 \%$ after exposure to $0.2,0.3$, and 0.4 $\mu \mathrm{M}$ of PT, respectively, in KYSE 30 cells, and from $2.41 \pm 0.12 \%$ in the control group to $6.52 \pm 0.82 \%$, $24.90 \pm 0.64 \%$, and $64.50 \pm 0.74 \%$, respectively, in KYSE 450 cells. Taken together, the overall results reveal that PT-induced apoptosis in ESCC cells is related to the activation of mitochondrial and caspase-dependent pathways. 

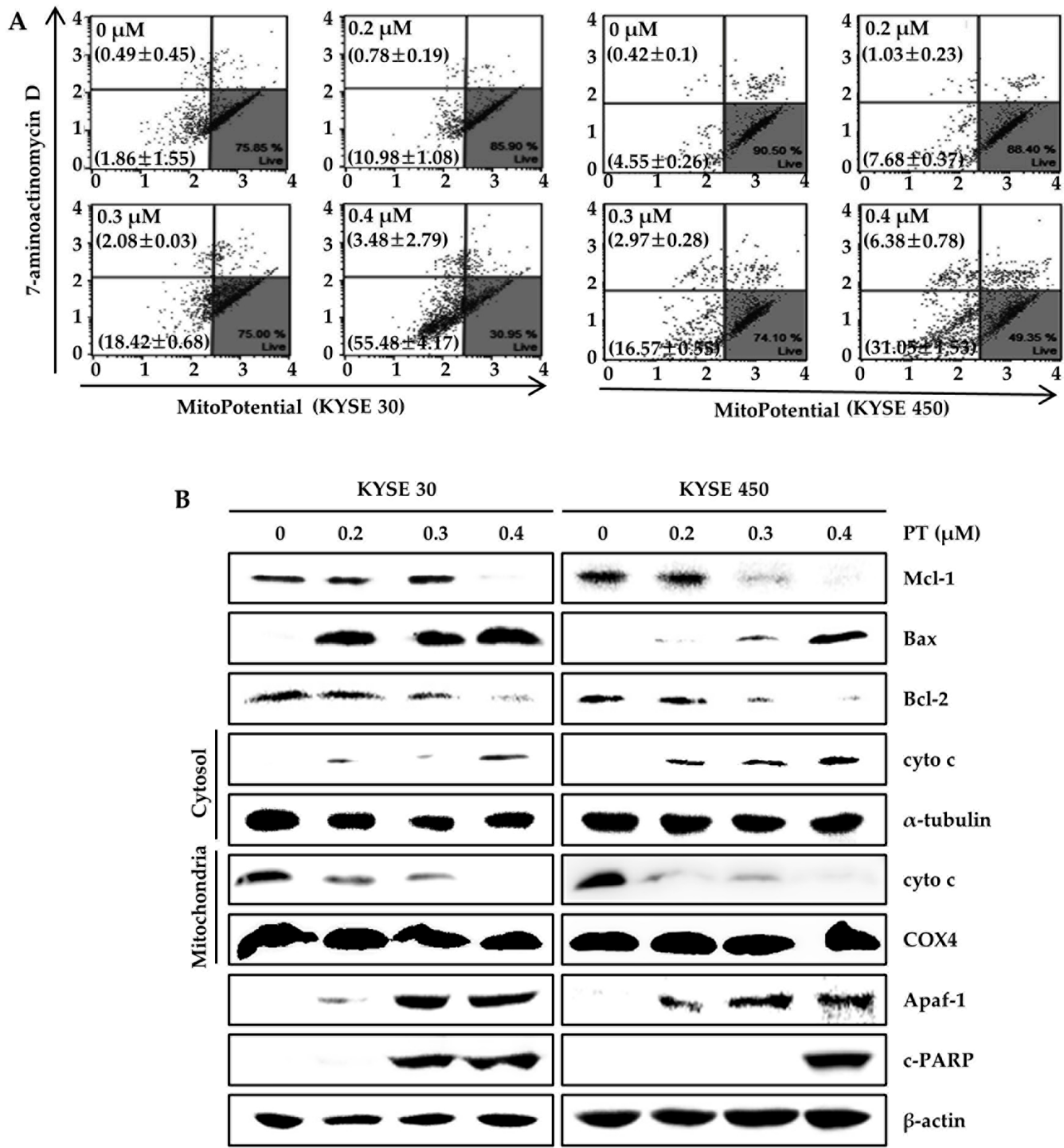

Figure 5. Effects of PT on mitochondrial dysfunction-mediated signaling in ESCC cells. (A) mitochondrial membrane potential (MMP) was evaluated by staining with MitoPotential dye, and 7-AAD and was analyzed using the Muse ${ }^{\mathrm{TM}}$ Cell Analyzer. The lower and upper left quadrants show mean MMP depolarization associated with early and late apoptosis, respectively. Values represent the means \pm SD. Data are representative of three independent experiments; (B) Western blot analysis was conducted to examine the protein expression of Mcl-1, Bax, Bcl-2, Apaf-1, and c-PARP after cells were exposed to PT at different concentrations $(0,0.2,0.3$, and $0.4 \mu \mathrm{M})$ for $48 \mathrm{~h}$. Mitochondrial and cytosolic extracts were processed via western blot using the anti-cyto $\mathrm{c}$ antibody. $\beta$-actin, $\alpha$-tubulin, and COX4 were used as the loading controls in the whole cell, cytoplasm, or mitochondria, respectively. 

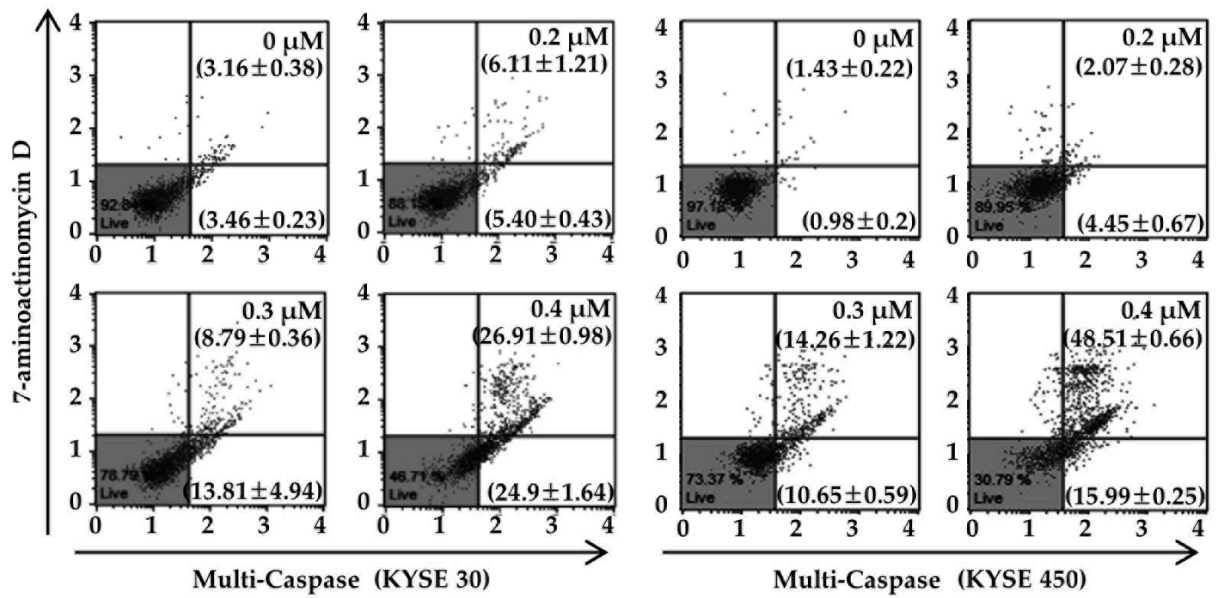

Figure 6. Effects of PT on caspase activation in ESCC cells. KYSE 30 and KYSE 450 cells were treated with different concentrations of PT $(0,0.2,0.3$, and $0.4 \mu \mathrm{M})$ for $48 \mathrm{~h}$. Activities of multiple caspases (caspase-1, -3, -4, -5, -6, -7, -8, and -9) were measured with a Muse ${ }^{\mathrm{TM}}$ cell analyzer using a Muse ${ }^{\mathrm{TM}}$ Multi-Caspase Kit. Each quadrant shows a population of viable cells (lower-left panel), a cell population with caspase activity (lower-right panel), late stages including caspase activity/dead cells (upper-right panel), and dead cells (upper-left panel) in each experimental group. Values represent the means (caspase-positive) \pm SD. Data are representative of three independent experiments.

\section{Discussion}

ESCC is a major health challenge worldwide, and effective treatment has yet to be identified [20]. It is imperative to explore new treatments, as existing treatments have severe side effects and poor efficacy. According to a 2018 study, weight loss and other side effects were not observed when Free PT was treated in mice xenografts to assess antitumor activity [21]. In previous reports, PT, a natural phytochemical compound, has been showed to inhibit cancers, including cervical carcinoma, breast, and prostate cancers [22,23]. Although the anti-neoplastic efficacy of PT against numerous cancers has been reported [2], its efficacy and precise pharmacological mechanisms in ESCC were not reported until now. In this study, we demonstrated that PT induced apoptosis via mitochondrial pathways in ESCC cell lines, as evidenced by an elevation in subG1 cells, phosphatidylserine externalization, ROS generation, and the loss of MMP, as well as the activation of MAPKs and caspases. Cancer cells carry defects involving the maintenance of homeostasis in cell proliferation, which is a critical hallmark of apoptosis [24,25]. In the current study, we are the first to demonstrate that PT significantly inhibits the growth of ESCC cells (Figure 1B-H). Among the five ESCC cell lines, KYSE 30 and KYSE 450 have analogical genetic backgrounds and characteristics [26] and have been selected for in-depth analysis because they show similar responses to PT treatment. The $\mathrm{IC}_{50}$ concentrations of PT in KYSE 30 and KYSE 450 cells were 0.27 and $0.3 \mu \mathrm{M}$, respectively. In addition, colony formation was sharply decreased in PT-treated cells, which further indicates the growth-inhibitory action of PT (Figure 1G,H). Based on the foregoing findings, we also investigated biomarkers of apoptotic cell death, such as phosphatidylserine externalization, with annexin-V staining (Figure 1I). A loss of plasma membrane asymmetry mediated by phosphatidylserine externalization is associated with early apoptotic phenomena [27]. The significant increase in the apoptotic rate of PT-treated cells indicates that PT causes apoptosis via phosphatidylserine externalization on the cytoplasmic surface of the cell membrane (Figure 1I). A previous study showed that cellular mechanisms ensure healthy cell progression and proliferation through cell cycle arrest [28]. Cyclin B1 and cdc2 are the key regulators of the G2/M phase transition of the cell cycle, and these regulatory proteins are inhibited by p21, which serves as a cyclin-dependent kinase-inhibiting protein $[28,29]$. PT significantly increased the G2/M phase and sub-G1 populations in the cell cycle progression of KYSE 30 and KYSE 450 cells (Figure 2A,B). Additionally, PT induced an increase in p21 and p27 protein levels, whereas it decreased 
the expression of cyclin B1 and cdc2. These results suggest that PT exerts an anti-cancer effect on ESCC cells via regulation of cell cycle progression. Intracellular ROS generation stimulates ER stress, and these species enhance ER stress-mediated apoptosis [30]. In the present study, the production of cellular ROS showed that the density of ROS-positive ESCC cells is elevated by PT treatment in a dose-dependent manner (Figure 3A). It is well known that ER stress-activated JNK and p38 trigger mitochondria-dependent apoptosis in various cancer cells [31]. PT significantly induced the phosphorylation of p38 and JNK in a dose-dependent manner (Figure 4). JNK and p38 activation play an important role in the induction of apoptotic cell death in response to ER stress [31]. PT enhanced the protein levels of DR4, DR5 and ER stress markers CHOP and GRP78, indicating the pro-survival signaling of ER stress responses (Figure 3B) [32,33]. These results further suggest that PT induces ER stress-mediated apoptosis in ESCC cells. MMP is essential for the generation of ATP to modulate physiological activity, and a collapse of MMP is an indicator of cellular integrity in the early stages of apoptosis [34,35]. PT treatment increases the percentage of depolarized cells, indicating a loss of MMP in PT-induced apoptosis (Figure 5A). The levels of apoptosis-related proteins, the Bcl-2 family, correlate with the levels of MMP [36]. The loss of MMP promotes the efflux of cyto $c$ to the cytosol and leads to the formation of a apoptosome-deoxyadenosine triphosphate-dependent complex, which consists of cyto $c$ and Apaf-1 $[37,38]$. PT was shown to increase the expression of Bax, Apaf-1, and c-PARP and decrease the levels of Mcl-1 and Bcl-2 in ESCC cells. Treatment with various concentrations of PT also induced the release of cyto $c$ into the cytosol (Figure 5B). Previous studies have reported that the release of cyto $\mathrm{c}$ from the mitochondria into the cytoplasm activates caspase 3, 8 , and 9 and, in turn, results in single-stranded and double-stranded DNA breaks [39]. Interestingly, incubation with PT induces dose-dependent activation of multiple caspases (caspase-1, -3, -4, -5, -6, -7, -8, and -9) in KYSE 30 and KYSE 450 cells (Figure 6). It is possible that apoptosis is mediated via the mitochondrial activation of the caspase cascade in ESCC cells.

\section{Conclusions}

This study demonstrated for the first time that PT exerts its anti-cancer effects on ESCC cells via mitochondrial apoptotic pathways. Our findings elucidate the mechanism of PT-induced cellular apoptosis, suggesting that PT is a potential chemotherapeutic agent.

Author Contributions: Conceptualization, G.Y., M.-H.L., A.-W.K., H.-N.O., S.-S.C., J.-S.C., and K.L.; methodology, G.Y., M.-H.L., A.-W.K., H.-N.O., S.-S.C., J.-S.C., K.L., J.-I.C., and J.-H.S.; software, G.Y. and M.-H.L.; validation, G.Y., M.-H.L., A.-W.K., H.-N.O., S.-S.C., J.-S.C., and K.L.; formal analysis, G.Y., M.-H.L., A.-W.K., H.-N.O., S.-S.C., J.-S.C., and K.L.; investigation, G.Y., M.-H.L., A.-W.K., H.-N.O., S.-S.C., J.-S.C., K.L., J.-I.C., and J.-H.S.; resources, J.-I.C. and J.-H.S.; data curation, G.Y., M.-H.L., A.-W.K., H.-N.O., S.-S.C., J.-S.C., and K.L.; writing-original draft preparation, M.-H.L. and J.-S.C.; writing-review and editing, M.-H.L. and J.-S.C.; supervision, J.-I.C. and J.-H.S. All authors have read and agreed to the published version of the manuscript.

Funding: This research was funded by Basic Science Research program of National Research Foundation Korea, grant number 2019R1A2C1005899.

Acknowledgments: This research was supported by the Basic Science Research program through the National Research Foundation Korea Funded by the Ministry of Education, Science, and Technology (2019R1A2C1005899). This work was carried out by the Convergence Research Laboratory established by the Mokpo National University (MNU) Innovation Support Project.

Conflicts of Interest: The authors declare the absence of any conflict of interest.

\section{References}

1. Zhang, D.; Zhou, X.; Bao, W.; Chen, Y.; Cheng, L.; Qiu, G.; Sheng, L.; Ji, Y.; Du, X. Plasma fibrinogen levels are correlated with postoperative distant metastasis and prognosis in esophageal squamous cell carcinoma. Oncotarget 2015, 6, 38410-38420. [CrossRef] [PubMed] 
2. Wang, K.; Johnson, A.; Ali, S.M.; Klempner, S.J.; Bekaii-Saab, T.; Vacirca, J.L.; Khaira, D.; Yelensky, R.; Chmielecki, J.; Elvin, J.A.; et al. Comprehensive Genomic Profiling of Advanced Esophageal Squamous Cell Carcinomas and Esophageal Adenocarcinomas Reveals Similarities and Differences. Oncologist 2015, 20, 1132-1139. [CrossRef] [PubMed]

3. Sugase, T.; Takahashi, T.; Serada, S.; Nakatsuka, R.; Fujimoto, M.; Ohkawara, T.; Hara, H.; Nishigaki, T.; Tanaka, K.; Miyazaki, Y.; et al. Suppressor of cytokine signaling-1 gene therapy induces potent antitumor effect in patient-derived esophageal squamous cell carcinoma xenograft mice. Int. J. Cancer 2017, 140, 2608-2621. [CrossRef] [PubMed]

4. Silveira, A.L.; Faheina-Martins, G.V.; Maia, R.C.; Araujo, D.A. Compound A398, a novel podophyllotoxin analogue: Cytotoxicity and induction of apoptosis in human leukemia cells. PLoS ONE 2014, 9, e107404. [CrossRef] [PubMed]

5. Zupko, I.; Jaeger, W.; Topcu, Z.; Wu, C.C. Anticancer Properties of Natural Products. Biomed. Res. Int. 2015, 2015, 242070. [CrossRef] [PubMed]

6. Blowman, K.; Magalhaes, M.; Lemos, M.F.L.; Cabral, C.; Pires, I.M. Anticancer Properties of Essential Oils and Other Natural Products. Evid. Based Complement. Alternat. Med. 2018, 2018, 3149362. [CrossRef] [PubMed]

7. Cheng, W.H.; Shang, H.; Niu, C.; Zhang, Z.H.; Zhang, L.M.; Chen, H.; Zou, Z.M. Synthesis and Evaluation of New Podophyllotoxin Derivatives with in Vitro Anticancer Activity. Molecules 2015, 20, 12266-12279. [CrossRef]

8. Liu, Y.Q.; Tian, J.; Qian, K.; Zhao, X.B.; Morris-Natschke, S.L.; Yang, L.; Nan, X.; Tian, X.; Lee, K.H. Recent progress on C-4-modified podophyllotoxin analogs as potent antitumor agents. Med. Res. Rev. 2015, 35, 1-62. [CrossRef]

9. Zhang, L.; Zhang, Z.; Chen, F.; Chen, Y.; Lin, Y.; Wang, J. Aromatic heterocyclic esters of podophyllotoxin exert anti-MDR activity in human leukemia K562/ADR cells via ROS/MAPK signaling pathways. Eur. J. Med. Chem. 2016, 123, 226-235. [CrossRef]

10. Singh, A.; Yashavarddhan, M.H.; Kalita, B.; Ranjan, R.; Bajaj, S.; Prakash, H.; Gupta, M.L. Podophyllotoxin and Rutin Modulates Ionizing Radiation-Induced Oxidative Stress and Apoptotic Cell Death in Mice Bone Marrow and Spleen. Front. Immunol. 2017, 8, 183. [CrossRef]

11. Jiang, Z.; Song, F.; Li, Y.; Xue, D.; Zhao, N.; Zhang, J.; Deng, G.; Li, M.; Liu, X.; Wang, Y. Capsular Polysaccharide of Mycoplasma ovipneumoniae Induces Sheep Airway Epithelial Cell Apoptosis via ROS-Dependent JNK/P38 MAPK Pathways. Oxid. Med. Cell Longev. 2017, 2017, 6175841. [CrossRef]

12. Lin, C.L.; Lee, C.H.; Chen, C.M.; Cheng, C.W.; Chen, P.N.; Ying, T.H.; Hsieh, Y.H. Protodioscin Induces Apoptosis Through ROS-Mediated Endoplasmic Reticulum Stress via the JNK/p38 Activation Pathways in Human Cervical Cancer Cells. Cell Physiol. Biochem. 2018, 46, 322-334. [CrossRef] [PubMed]

13. Li, J.; He, J.; Fu, Y.; Hu, X.; Sun, L.Q.; Huang, Y.; Fan, X. Hepatitis B virus X protein inhibits apoptosis by modulating endoplasmic reticulum stress response. Oncotarget 2017, 8, 96027-96034. [CrossRef] [PubMed]

14. Onyeagucha, B.; Subbarayalu, P.; Abdelfattah, N.; Rajamanickam, S.; Timilsina, S.; Guzman, R.; Zeballos, C.; Eedunuri, V.; Bansal, S.; Mohammad, T.; et al. Novel post-transcriptional and post-translational regulation of pro-apoptotic protein BOK and anti-apoptotic protein Mcl-1 determine the fate of breast cancer cells to survive or die. Oncotarget 2017, 8, 85984-85996. [CrossRef] [PubMed]

15. Jiang, Y.; Wang, X.; Hu, D. Furanodienone induces G0/G1 arrest and causes apoptosis via the ROS/MAPKs-mediated caspase-dependent pathway in human colorectal cancer cells: A study in vitro and in vivo. Cell Death Dis. 2017, 8, e2815. [CrossRef]

16. Zhu, J.; Yu, W.; Liu, B.; Wang, Y.; Shao, J.; Wang, J.; Xia, K.; Liang, C.; Fang, W.; Zhou, C.; et al. Escin induces caspase-dependent apoptosis and autophagy through the ROS/p38 MAPK signalling pathway in human osteosarcoma cells in vitro and in vivo. Cell Death Dis. 2017, 8, e3113. [CrossRef]

17. Li, H.Y.; Zhang, J.; Sun, L.L.; Li, B.H.; Gao, H.L.; Xie, T.; Zhang, N.; Ye, Z.M. Celastrol induces apoptosis and autophagy via the ROS/JNK signaling pathway in human osteosarcoma cells: An in vitro and in vivo study. Cell Death Dis. 2015, 6, e1604. [CrossRef]

18. Zhang, J.; Chen, Q.; Wang, S.; Li, T.; Xiao, Z.; Lan, W.; Huang, G.; Cai, X. alpha-Mangostin, A Natural Xanthone, Induces Apoptosis and ROS Accumulation in Human Rheumatoid Fibroblast-Like Synoviocyte MH7A Cells. Curr. Mol. Med. 2017, 17, 375-380. [CrossRef] 
19. Oh, H.N.; Oh, K.B.; Lee, M.H.; Seo, J.H.; Kim, E.; Yoon, G.; Cho, S.S.; Cho, Y.S.; Choi, H.W.; Chae, J.I.; et al. JAK2 regulation by licochalcone $H$ inhibits the cell growth and induces apoptosis in oral squamous cell carcinoma. Phytomedicine 2019, 52, 60-69. [CrossRef]

20. Han, G.; Wu, Z.; Zhao, N.; Zhou, L.; Liu, F.; Niu, F.; Xu, Y.; Zhao, X. Overexpression of stathmin plays a pivotal role in the metastasis of esophageal squamous cell carcinoma. Oncotarget 2017, 8, 61742-61760. [CrossRef]

21. Zhou, H.; Lv, S.; Zhang, D.; Deng, M.; Zhang, X.; Tang, Z.; Chen, X. A polypeptide based podophyllotoxin conjugate for the treatment of multi drug resistant breast cancer with enhanced efficiency and minimal toxicity. Acta Biomater. 2018, 73, 388-399. [CrossRef] [PubMed]

22. Hu, L.L.; Zhou, X.; Zhang, H.L.; Wu, L.L.; Tang, L.S.; Chen, L.L.; Duan, J.L. Exposure to podophyllotoxin inhibits oocyte meiosis by disturbing meiotic spindle formation. Sci. Rep. 2018, 8, 10145. [CrossRef] [PubMed]

23. Xie, S.; Li, G.; Qu, L.; Zhong, R.; Chen, P.; Lu, Z.; Zhou, J.; Guo, X.; Li, Z.; Ma, A.; et al. Podophyllotoxin Extracted from Juniperus sabina Fruit Inhibits Rat Sperm Maturation and Fertility by Promoting Epididymal Epithelial Cell Apoptosis. Evid. Based Complement. Alternat. Med. 2017, 2017, 6958982. [CrossRef] [PubMed]

24. Hanahan, D.; Weinberg, R.A. Hallmarks of cancer: The next generation. Cell 2011, 144, 646-674. [CrossRef] [PubMed]

25. Tower, J. Programmed cell death in aging. Ageing Res. Rev. 2015, 23, 90-100. [CrossRef] [PubMed]

26. Hao, J.J.; Shi, Z.Z.; Zhao, Z.X.; Zhang, Y.; Gong, T.; Li, C.X.; Zhan, T.; Cai, Y.; Dong, J.T.; Fu, S.B.; et al. Characterization of genetic rearrangements in esophageal squamous carcinoma cell lines by a combination of M-FISH and array-CGH: Further confirmation of some split genomic regions in primary tumors. BMC Cancer 2012, 12, 367. [CrossRef]

27. Siedlecka-Kroplewska, K.; Wronska, A.; Stasilojc, G.; Kmiec, Z. The Designer Drug 3-Fluoromethcathinone Induces Oxidative Stress and Activates Autophagy in HT22 Neuronal Cells. Neurotox. Res. 2018. [CrossRef]

28. Yu, H.; Yin, S.; Zhou, S.; Shao, Y.; Sun, J.; Pang, X.; Han, L.; Zhang, Y.; Gao, X.; Jin, C.; et al. Magnolin promotes autophagy and cell cycle arrest via blocking LIF/Stat3/Mcl-1 axis in human colorectal cancers. Cell Death Dis. 2018, 9, 702. [CrossRef]

29. Chang, C.C.; Hung, C.M.; Yang, Y.R.; Lee, M.J.; Hsu, Y.C. Sulforaphane induced cell cycle arrest in the G2/M phase via the blockade of cyclin B1/CDC2 in human ovarian cancer cells. J. Ovarian Res. 2013, 6, 41. [CrossRef]

30. Rouault-Pierre, K.; Lopez-Onieva, L.; Foster, K.; Anjos-Afonso, F.; Lamrissi-Garcia, I.; Serrano-Sanchez, M.; Mitter, R.; Ivanovic, Z.; de Verneuil, H.; Gribben, J.; et al. HIF-2alpha protects human hematopoietic stem/progenitors and acute myeloid leukemic cells from apoptosis induced by endoplasmic reticulum stress. Cell Stem Cell 2013, 13, 549-563. [CrossRef]

31. Chen, W.Y.; Hsieh, Y.A.; Tsai, C.I.; Kang, Y.F.; Chang, F.R.; Wu, Y.C.; Wu, C.C. Protoapigenone, a natural derivative of apigenin, induces mitogen-activated protein kinase-dependent apoptosis in human breast cancer cells associated with induction of oxidative stress and inhibition of glutathione S-transferase pi. Investig. New Drugs 2011, 29, 1347-1359. [CrossRef] [PubMed]

32. Gu, L.L.; Shen, Z.L.; Li, Y.L.; Bao, Y.Q.; Lu, H. Oxymatrine Causes Hepatotoxicity by Promoting the Phosphorylation of JNK and Induction of Endoplasmic Reticulum Stress Mediated by ROS in LO2 Cells. Mol. Cells 2018, 41, 401-412. [CrossRef] [PubMed]

33. Shen, M.; Wang, L.; Wang, B.; Wang, T.; Yang, G.; Shen, L.; Wang, T.; Guo, X.; Liu, Y.; Xia, Y.; et al. Activation of volume-sensitive outwardly rectifying chloride channel by ROS contributes to ER stress and cardiac contractile dysfunction: Involvement of CHOP through Wnt. Cell Death Dis. 2014, 5, e1528. [CrossRef] [PubMed]

34. Ansari, S.S.; Sharma, A.K.; Soni, H.; Ali, D.M.; Tews, B.; Konig, R.; Eibl, H.; Berger, M.R. Induction of ER and mitochondrial stress by the alkylphosphocholine erufosine in oral squamous cell carcinoma cells. Cell Death Dis. 2018, 9, 296. [CrossRef] [PubMed]

35. Zhou, X.; Wang, H.Y.; Wu, B.; Cheng, C.Y.; Xiao, W.; Wang, Z.Z.; Yang, Y.Y.; Li, P.; Yang, H. Ginkgolide K attenuates neuronal injury after ischemic stroke by inhibiting mitochondrial fission and GSK-3beta-dependent increases in mitochondrial membrane permeability. Oncotarget 2017, 8, 44682-44693. [CrossRef] [PubMed] 
36. Chou, W.H.; Liu, K.L.; Shih, Y.L.; Chuang, Y.Y.; Chou, J.; Lu, H.F.; Jair, H.W.; Lee, M.Z.; Au, M.K.; Chung, J.G. Ouabain Induces Apoptotic Cell Death Through Caspase- and Mitochondria-dependent Pathways in Human Osteosarcoma U-2 OS Cells. Anticancer Res. 2018, 38, 169-178. [CrossRef]

37. Su, L.Y.; Shi, Y.X.; Yan, M.R.; Xi, Y.; Su, X.L. Anticancer bioactive peptides suppress human colorectal tumor cell growth and induce apoptosis via modulating the PARP-p53-Mcl-1 signaling pathway. Acta Pharmacol. Sin. 2015, 36, 1514-1519. [CrossRef]

38. Wang, R.; Ma, L.; Weng, D.; Yao, J.; Liu, X.; Jin, F. Gallic acid induces apoptosis and enhances the anticancer effects of cisplatin in human small cell lung cancer H446 cell line via the ROS-dependent mitochondrial apoptotic pathway. Oncol. Rep. 2016, 35, 3075-3083. [CrossRef]

39. Huang, X.; Zou, L.; Yu, X.; Chen, M.; Guo, R.; Cai, H.; Yao, D.; Xu, X.; Chen, Y.; Ding, C.; et al. Salidroside attenuates chronic hypoxia-induced pulmonary hypertension via adenosine A2a receptor related mitochondria-dependent apoptosis pathway. J. Mol. Cell Cardiol. 2015, 82, 153-166. [CrossRef] [PubMed]

(C) 2019 by the authors. Licensee MDPI, Basel, Switzerland. This article is an open access article distributed under the terms and conditions of the Creative Commons Attribution (CC BY) license (http://creativecommons.org/licenses/by/4.0/). 